\title{
Giant vesical calculus with carcinoma bladder: A rare entity
}

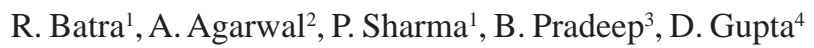 \\ ${ }^{1}$ Lecturer, ${ }^{2}$ Post Graduate, ${ }^{4}$ Professor \& Head, Department of Surgery, ${ }^{3}$ Lecturer of Anatomy, Mahatma Gandhi Institute of \\ Medical Sciences, Sevagram, India
}

\begin{abstract}
A 60 year old male attended with history of dribbling of urine for one year along with frequent passing of urine at night for last 15-20 days. Rectal examination showed suggesting of 2 grad prostrate enlargement. Ultrasound shows vesicle calculus with no prostrate enlargement. At cystolithotomy, calculus (10x8x5cm) was noted. Histopathology shows keratinising squamous cell carcinoma. Postoperatively radiotherapy was done. Vesico cutaneous fistula was developed that healed subsequently.
\end{abstract}

Key words: Dribbling, prostrate, calculus.

\section{Introduction}

Giant vesical calculus weighing more than $100 \mathrm{~g}$ is a rare entity ${ }^{1}$. Fewer than 30 reports are available in the English literature having weight of the stone more than $100 \mathrm{gm} .{ }^{1}$ The largest vesical calculus is of 6294 gram reported so far. ${ }^{2}$ Males are affected more than the females. We report a case of vesical calculus weighing 525 gram in a male patient which was associated with carcinoma bladder.

\section{Case history}

A 60 year old male presented with dribbling of urine since 1year which was present throughout the day \& was small in amount. It was associated with increase frequency of micturation since 15-20 days 20times during day and 15 times during night. The amount of urine passed each time is small \& sense of incomplete

Correspondence: R. Batra

Emaildrravibatra@rediffmail.com emptying is present. It was associated with burning micturation, haematuria, dysuria, hesitancy.

On examination patient had stable vitals and on per abdomen examination it was soft and nontender, per rectal examination s/o grade 2 prostatomegaly with hard to firm feel, mucosa freely mobile. Per urethral catheterization attemted but failed. On investigations haemogram was found to be normal and plain radiography suggested giant vesical calculus.(Figure 1) Ultrasound revealed large vesical calculus with no prostratomegaly. His investigations suggested S.creat2.3mg/dl, S.urea-99mg/dl, S.Na-126, S.K-4.4, Haemoglobin-9.6mg/dl

Patient underwent cystolithotomy and a $10 \times 8 \times 5 \mathrm{~cm}$ calculus present which was associated with papillary growth arising from posterior \& lateral wall of bladder which was fixed to the bladder wall and was occupying all most the whole of the bladder lumen. Histopathological examination was suggestive of (BI) 
Journal of College of Medical Sciences-Nepal,2010,Vol-6,No-4

keratinizing squamous cell carcinoma (Figure 2). Post operatively patient was given radiotherapy and is currently under follow-up. During the follow up period patient developed vesicocutaneous fistula which healed on its own subsequently.

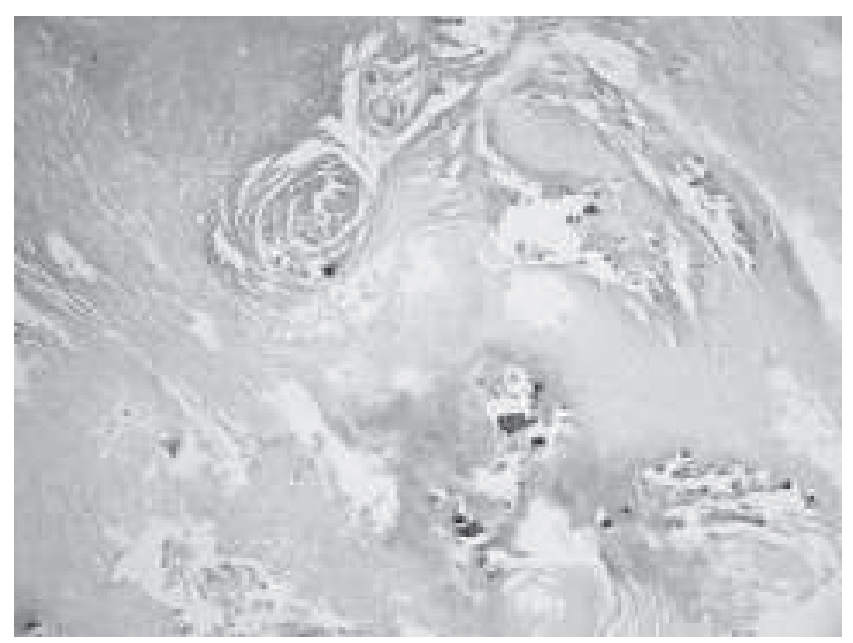

Figure 1: Histopathology of the excised mass

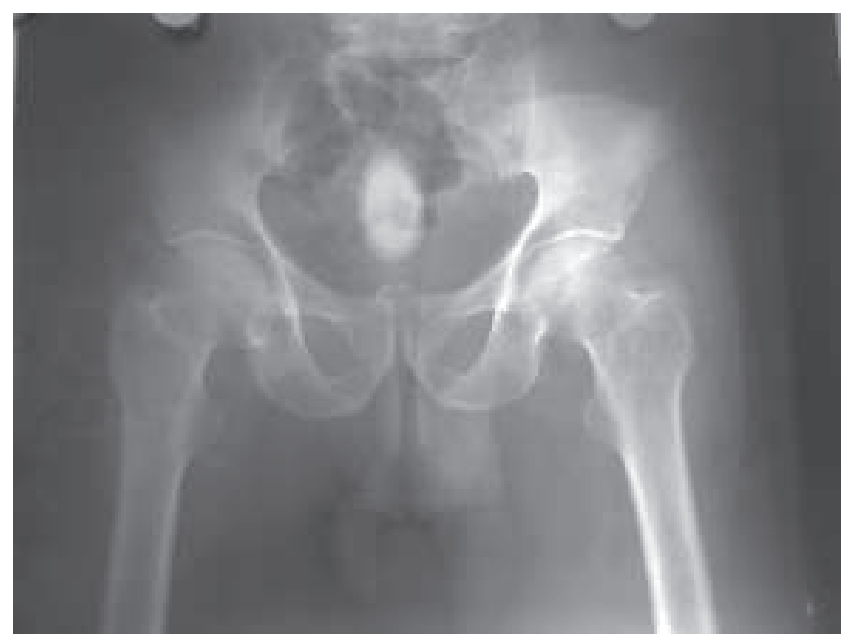

Figure 2: Radiographic view of the calculus.

\section{Discussion}

Calculus disease of the urinary system is known since a long time. Vesical calculi though commonly found, giant vesical calculi are rare. Vesical calculi are commonly secondary to the renal stones or to the bladder outlet obstruction and bladder diverticulum. ${ }^{3}$ These calculi are seen commonly in males due to benign prostatic hypertrophy or urethral stricture. Rarer causes as trauma, catheterisation, neurogenic bladder, foreign body have also been reported. Bladder stones are reported around a foreign body, sutures, catheters or other objects introduced in the bladder. Earlier massive or giant vesical calculus formed around arterial graft, which was incorporated in the bladder have been reported ${ }^{3}$.

These giant calculi are thought to develop from a single ureteric calculus or from the nidus of the infected material with a progressive layering of the calcified matrix. Similarly formation of a large vesical calculus as a result of coalescence of 2 or more calculi. ${ }^{4}$

Majority compositions of the vesical calculi include triple phosphate, calcium carbonate, and calcium oxalate. The massive or giant vesical calculus of 235 gram with uric acid as the major component with asymmetrical calcium oxalate have also been reported. ${ }^{1}$

Patients with giant vesical calculus usually present with recurrent urinary tract infection, azotaemia and retention of urine. Surgical treatment of vesical calculi has evolved over years from 'blind' insertion of crushing forceps into the bladder to open surgical removal or extracorporeal fragmentation. Open surgery has been the best-recommended modality for large stones. ${ }^{5}$

In small or moderate calculi, endosurgical procedures as optical mechanical cystolithotripsy have an added advantage as it can be combined with corrective procedure for bladder outlet obstruction. ${ }^{6}$ Zhaowu et al have recommended that Electrohydraulic shockwave lithotripsy (EHSWL) preferably to be avoided in large, hard vesical calculi and if the stone is in the diverculum or stuck to the mucosa. ${ }^{7}$ 
R. Batra et al, Giant vesical calculus with carcinoma bladder: A rare entity

\section{References}

1. R.M. Becher, B.M. Tolia, H.R Newman. Giant vesical calculus. JAMA 1976;239(21):2272-3.

2. J.H. Harrison. Campbell's Urology. 4th ed., Philadelphia WB Saunders Co. 1978;853-4.

3. P.A. Pomerantz. Giant vesical calculus formed around arterial graft incorporated into bladder. Urology. 1989;33(1):57-8.

4. H.J.E. Lewi, A. White, B.J. Abel et al. Fused vesical calculi. Urology 1987;30(3):267-8.
5. P.N. Maheshwari, A.T. Oswal, M. Bansal. Percutaneous cystolithotomy for vesical calculi :a better approach.Tech-Urol1999;5(1):40-2.

6. R. Asci, Z. Aybek, S. Sarikaya, et al. The management of vesical calculi with optical mechanical cystolithotripsy and transurethral prostatectomy is it safe and effective? BJU Inter 1999;84:332-6.

7. Z. Zhaowu, Xiwen, Z. Fenling. Experience with electrohydraulic shockwave lithotripsy in the treatment of vesical calculi. BJU 1988;61:498-9. 